\title{
25 Research Square \\ Service Efficiency of Nursing Homes Based on DEA and Tobit Model: a Longitudinal Study in China
}

\section{Liangwen Zhang}

Xiamen University

\section{Ying Han}

Xiamen University

Ya Fang ( $\nabla$ fangya@xmu.edu.cn )

Xiamen University https://orcid.org/0000-0002-9895-3234

\section{Research}

Keywords: DEA, Tobit model, Service efficiency, Nursing homes

Posted Date: January 28th, 2021

DOI: https://doi.org/10.21203/rs.3.rs-153192/v1

License: (1) This work is licensed under a Creative Commons Attribution 4.0 International License. Read Full License 


\section{Abstract}

Background: Low utilization of care resources in China continues to be a challenging problem even though the rapid development of pension services. However, few studies have explored the utilization of care services with either the production of nursing homes at a national and longitudinal level.

Methods: The present study analyzes the spatio-temporal distribution of TE and productivity of nursing homes by using the data from China Civil Affairs statistical yearbook (2012-2016). Analysis was conducted based on the Data Envelopment Analysis and Tobit model, which have been widely applied to integrate several quality measures as a comprehensive benchmark.

Results: The average TE, PTE and SE of nursing homes were 0.909. 0.928 and 0.979 from 2012 to 2016, respectively. The TE and SE decreased from 2012 to 2014, but improved after 2014. TE is 0.98 in the Eastern region, 0.93 of that in the Central region and 0.91 of that in the Western region, with a decrease range of $2 \%, 7 \%$ and $9 \%$, respectively. The average improvement range of the five input indexes of the non-DEA effective nursing homes was $27.26 \%, 20.62 \%, 19.77 \%, 22.04 \%$, and $38.84 \%$, respectively. The influencing factors of efficiency value of nursing homes indicated that if there are more social workers, more patients in the nursing homes, and more employees who are aged 56 and above, the TE and productivity of nursing homes will be higher.

Conclusion: We find that TE of nursing homes in Western regions are all at the lowest, as the current facilities can neither provide equitable nor optimal access and utilization. The decline of the efficiency and productivity before the healthcare reform implementation in 2014 was significant, where the influencing factors could be age and gender of employees, the number of social workers, and older people. Finally, suggestions are put forward for improving the efficiency of allocation and utilization of care services.

\section{Background}

Population aging has been an increasingly challenging problem around the world [1]. Specifically, in China, $11.9 \%$ of the population was over 65 years old in 2018, while the proportion is still rising, exceeding that of most EU countries [1, 2]. A report in 2017 showed that there were about 40.63 million disabled elderly people in the country [3] and it is projected that 68 million of the older people in China will experience some degrees of disabilities in China by 2030[4]. However, in the context of rapidly increasing aging population and disabled elderly, the ever-wakening family-oriented care function has made public long-term care facilities (LTCFs) resources increasingly strained to provide sufficient, efficient living care, rehabilitation care and emergency rescue [5]. In addition, the traditional family-oriented care function for the elderly is constantly weakening. Therefore, the demand for equitable and efficient LTCFs will continue to increase as years go by, which can provide professional living care, rehabilitation care and emergency rescue services for the elderly. 
In order to solve the problems brought about by the aging of the population, Chinese government has arranged a total investment of 9.17 billion yuan in the central budget, focused on supporting the construction of nursing homes for the elderly and facilities for elderly care with integrated medical care. By the end of January 2019, there were 163,800 nursing homes and various types of facilities in the country, of which 29,700 were nursing homes, 46,600 were community service facilities for elderly, and 87,300 were mutual care facilities. A total of 7.46 million beds were provided for the various types of elderly care services, and among them, there are 3.928 million beds in nursing homes, while only account for $50 \%$ bed occupancy rate [6]. Total beds account for $3 \%$ of the country's older population. Generally, developed countries can reach $5 \%-7 \%$. From the calculation, the number of beds required should be at least 12.45 million to accommodate China's elderly, who are in the need of long-term care (LTC) [7]. It has been further estimated that 300000 registered long-term care workers nationwide and over 40 million older people with disabilities who need care [8], the overall shortage of beds for the elderly, with a large space to adjust, showing a very obvious contradiction between supply and demand.

Various contradictions between supply and demand still inevitably occur in China, such as the serious shortage of beds, the corresponding number of nursing staff, the low level of professionalism, smallinfrastructure scale of residential care, and the lack of risk management system and the service evaluation system for elderly care $[9,10]$, plus insufficient inspections and ineffective enforcement of rules $[11,12]$. Therefore, how to effectively improve the service quality, service efficiency, and also the output efficiency of nursing homes in the process of increasing investment and rationally allocating service resources have become an urgent problem for both the government and academia.

With the deepening of the research on the service quality of nursing homes, foreign scholars began to pay more attention to the problem of inputs and outputs of the nursing homes at the same time. A sample survey was conducted in nursing homes in certain areas of Finland, Italy, Japan and Norway respectively, which investigated the relative efficiency and influencing factors, based on explorations on application of Data Envelopment Analysis (DEA) method and regression model [13-16]. DEA was defined as an advantageous non-parametric technique for evaluating performance in terms of relative efficiency in the presence of multiple inputs and outputs [17]. Efficiency can be simply used as a tool to explain the relationship between the inputs and outputs. And even technical efficiency (TE) can be applied to find out whether any waste can be eliminated without worsening any input or output [18].

Although most of researches in developed countries on the service efficiency of pension service institutions are relatively complete, their research approaches and results may not be applicable to China due to different levels of development. There exist amounts of shortcomings in the researches related to the efficiency of China's nursing homes. For example, some only focused on theoretical study for institutional planning of LTCFs, including the exploration of institution building and service standards, service contents, and service personnel[19], some mainly focused on individual nursing home in a certain province or city[20], while some others just proposed analytical methods, but lack quantitative studies, which cannot provide scientific basis for promoting the overall healthy development of the nursing homes in China from a macro perspective [21, 9]. In addition, most of the previous researches use the 
cross-sectional data to apply the single stage and DEA Tobit two-stage models in conducting a regional static research [22].

The purpose of this study is to make comprehensive evaluation of service efficiency and spatio-temporal variation of nursing homes in China, combined with DEA method and Tobit model to provide an evidence for decision-making by integrating and optimizing resource allocation, as well as to comprehensively improve the service efficiency of LTCFs.

\section{Methods}

\section{Data}

Data were obtained from the China Civil Affairs statistical yearbook [23], a national survey compiled by the Statistical Annual Report of the Social Service Industry and the reports of relevant departments, which is related to the social services in each year among all of the nursing homes in 31 provinces of China from 2012 to 2016. This project was deemed exempt from Institutional Review Board (IRB) review because the data are de-identified and publicly available.

\section{Data Envelopment Analysis}

DEA is an advantageous non-parametric technique for measuring the relative efficiency of homogeneous decision making units (DMUs) because of its advantages in dealing with multi-input and multi-output indicators [17]. DEA can handle multiple input and chromatography at the same time. Also, it doesn't need to set artificial weight coefficient [24]. Furthermore, it has nothing to do with the dimension in selecting the suitable input and output items and it avoids calculating the standard cost of each service [25]. Therefore, the DEA model can be regarded as the better choice for the purpose and current situation of the research on the comprehensive efficiency of nursing homes.

\section{Selection of the model}

\section{Charnes-Cooper-Rhodes (CCR)and Banker-Charnes Cooper (BCC)model}

DEA calculates a maximal performance measure for each DMU with the sole requirement that each DMU lie on or below the frontier [26]. The traditional DEA model mainly included CCR model based on constant returns to scale and BCC model with variable returns to scale [17]. The redial CCR model [27]and BCC model [28] suffers from one shortcoming; they neglect the slacks in the evaluation of efficiencies. To overcome this shortcoming efficiency scores can be computed using the "slack based" non-radial and non-oriented DEA model [29]. This paper measures the overall TE, pure technical efficiency (PTE) and scale efficiency (SE) of nursing homes. The final scores related to TE, PTE and SE were compared by Kruskal-Wallis test, given the sampling error.

\section{Slack-based model (SBM) model}


The Additive Model (AM) or SBM is based on input and output slacks [29]. In this study, a non-oriented and non-radial model known as SBM-DEA model has been used [30]. BCC model and SBM model all choose input-oriented. We used the input-oriented model in this demonstration. An input-oriented DEA model was used to compute TE scores of nursing care can be expressed by the following formula.

$$
\left\{\begin{array}{l}
\max \left[\theta-\varepsilon\left(e^{T} s^{-}+\hat{e}^{T} s^{+}\right)\right] \\
\sum_{j=1}^{n} x_{j} \lambda_{j}+s^{-}=\theta x_{0} \\
\sum_{j=1}^{n} y_{j} \lambda_{j}-s^{+}=y_{0} \\
\lambda_{j} \geq 0, j=1, \ldots, n, s^{+} \geq 0 ; s^{-} \geq 0
\end{array}\right.
$$

In the case of $\theta=1, S^{-}=0, S^{+}=0$, the nursing home is fully efficient, whereas $\theta<1$ means that a nursing home is inefficient. BCC model adds constraint conditions on the basis of CCR model:

$$
\sum_{j=1}^{\mathrm{n}} \lambda_{j}=1
$$

At this time, it means that the return on scale of DMU remains unchanged and reaches the maximum output scale. In addition, when $\sum_{j=1}^{n} \lambda_{j}=1<1$, this means that returns to scale are increasing. If the input of DMU is appropriately increased on the basis of the original input, the output will be increased by a higher proportion. Whereas $\sum_{j=1}^{n} \lambda_{j}=1>1$, it means diminishing returns to scale, and increasing input does not lead to a higher proportion of output. In addition, for the formula of SBM-DEA, please refer to the paper written by Mogha SK for details [31]. Due to TE values have truncated characteristics and efficiency values are relative, using general multiple regression models results in bias and parameter estimation instability [32].

\section{Malmquist model}

Productivity measures changes in a production unit's efficiency in transforming inputs into outputs from time $t$ to time $t+1$ [33]. It was generally used in panel data. MPI was named after Malmquist [34] and was introduced by Caves, Christensen and Diewert to evaluate productivity changes among different production units [35]. MPI (also called total factor productivity changes (TFPC)) can be decomposed into technical efficiency changes (TEC) and technological changes (TC). TEC can also be decomposed into pure technical efficiency changes (PTEC) and scale efficiency changes (SEC) [36]. The formula shown as following: 
$\mathrm{TFPC}=\mathrm{TEC} \times \mathrm{TC}=(\mathrm{PTEC} \times \mathrm{SEC}) \times \mathrm{TC}$

\section{DEA classification}

We adhere to all the assumptions made by the Troutt et al [37]. and the Seiford and Zhu [38] studies to classify the DMUs into Eastern, Central and Western regions. Assuming non-negative inputs and an output of unity for all the acceptable cases and using the DEA model proposed by Banker et al [39]. (Supplementary materials)

\section{Variable selection}

\section{Input-output indicators}

There is no consensus conclusion on the choice of input-output variables for the operation efficiency of old-age institutions [40]. Based on the theory of production factors in economics, input factors can be divided into capital, labor, and material inputs, and output factors can be divided into economic benefits and social benefits [41]. As LTCFs were labor-intensive industries. Scholars usually used fixed assets as capital input index and various types of institutional staff as human input index [42,9]. As in terms of material inputs, the actual number of beds was a resource that was easily controlled by managers in material resources. A number of studies considered the number of beds, the number of institutions and the original price of fixed assets as indicators of material resources $[43,18]$. In addition, the older care industry is a labor-intensive industry, the capital of the labor substitution is very small. Comprehensively, choosing human capital as input index is an appropriate index for efficiency comparison, like the main care resources including the number of social workers and the number of employees [44]. Therefore, the input indicators established in this article are the number of institutions, the number of employees at the end of the year, the original price of fixed assets, the number of social workers, the number of beds at the end of the year (Supplementary Table 1).

Output indicators are important in evaluating the quality and quantity of long-term care services [45]. However, most researchers only consider the input of human capital or financial capital, but fail to consider the service quality of pension service, which directly determine the final effect of elderly care and the development prospects of the residential care $[46,47]$. The service quality can be reflected by the number of the disabled, the number of partially disabled the number of complete independents and in residential cares at the end of the year. Therefore, the output indexes should include operating income, the number of disabled, the number of partially disabled and the number of independents in residential cares at the end of the year, and also the number of rehabilitation and medical outpatients (Supplementary Table 1). Supplementary Table 2 presented summary statistics of input-output variables.

\section{Results}

\section{Comparison of the efficiency of nursing homes in China from 2012 to 2016.}


Supplementary Table 3 summarized the annual mean TE, PTE and SE of the sample LTCFs from 2012 to 2016. The average TE, PTE and SE for the 5-year period were 0.909. 0.928 and 0.979, respectively, and TE, PTE, SE of nursing homes are significantly different among different years, as shown by the mean rank and Kruskal-Wallis test.

From 2012 to 2014 the number of nursing homes which are in effective TE, PTE and SE presented decreasing trend, while presented an increasing trend on the whole after 2014. (Supplementary Fig. 1 and Table 1)

Table 1

The number of nursing homes with effective TE, PTE and SE in various provinces

\begin{tabular}{|llll|}
\hline Year & Effective TE & Effective PTE & Effective SE \\
\hline 2012 & 18 & 19 & 18 \\
\hline 2013 & 15 & 18 & 15 \\
\hline 2014 & 12 & 17 & 12 \\
\hline 2015 & 20 & 22 & 20 \\
\hline 2016 & 16 & 22 & 16 \\
\hline mean & 16.2 & 19.6 & 16.2 \\
\hline Proportion & 0.522581 & 0.632258 & 0.522581 \\
\hline $\begin{array}{l}\text { Note: } \text { A score = } 1 \text { indicates Effective technical efficiency (TE), pure technical efficiency (PTE), scale } \\
\text { efficiency (SE) }\end{array}$ & & \\
\hline
\end{tabular}

\section{SBM model was used to calculate the changes in the DEA efficiency value of the LTCF across the country}

Figure 1 presented the distribution of SBM efficiency values in China's LTCFs. The results showed that the efficiency of LTCFs in the western region changes rapidly, with an effective TE from 2015 to 2016. The changes in the Eastern regions are second to the changes of the Western. The increase in the efficiency of LTCFs in the Western regions is greater than the Eastern region, while in the Central region is the worst. It was notable that from 2012 to 2016, LTCFs in Hebei, Inner Mongolia, Shanxi, Anhui and Yunnan provinces have never reached an effective TE.

\section{Malmquist productivity index}

It can be seen that under the overall evaluation model, the TFPC of LTCFs in 10 regions increased from 2012 to 2016. The average growth of LTCFs in Tibet was the highest, reaching $81.6 \%$. TEC of LTCFs in 10 provinces (Guizhou, Anhui, etc.) has declined, TEC of LTCFs in 7 provinces (Liaoning, Xinjiang, etc.) improved. TC of LTCFs in 8 provinces and municipalities has improved, but the extent of the improvement is small, only Tibet has the largest progress, reaching 79.2\%. PTEC of LTCFs in 6 provinces (Hainan, 
Guizhou, etc.) have declined, and PTEC of LTCFs in 8 provinces (Liaoning, Fujian, etc.) improved, Fujian Province had the largest increase. (Table 2).

Table 3 showed that, from 2012 to 2016 , the average TEC was 1.001, and the index increased or decreased by $1.1-26.4 \%$ in each year, with a large change range, among which the increase in 2015 was up to $26.4 \%$. The average value of TC is 0.983 , with an increase or decrease rate of less than $4 \%$ per year. After 2015, the trend of steady rise remains stable. The average PTEC was 1.003 , with a sharp increase of $19.8 \%$ in 2015 . The average value of SEC is 0.988 , which is in a stable development state. The average value of TFPC was 0.984 , and the maximum increase of TFPC in 2015 was $31.8 \%$. As shown in Supplementary Fig. 2, the five efficiency values of LTCFs in combined total of 31 provinces and municipalities reached the lowest in 2014 and the highest in 2015. During this period, the results showed a trend that initially went upward and then eventually downward. 
Table 2

The evaluation of Malmquist productivity index

\begin{tabular}{|c|c|c|c|c|c|c|}
\hline No. & DMUs & TEC & $\mathrm{TC}$ & PTEC & SEC & TFPC \\
\hline 1 & Beijing & 1 & 1.019 & 1 & 1 & 1.019 \\
\hline 2 & Tianjin & 1 & 1.055 & 1 & 1 & 1.055 \\
\hline 3 & Hebei & 0.988 & 0.919 & 0.987 & 1.001 & 0.908 \\
\hline 4 & Shanxi & 0.998 & 0.973 & 1.004 & 0.995 & 0.971 \\
\hline 5 & Inner Mongolia & 0.976 & 0.995 & 0.977 & 0.999 & 0.971 \\
\hline 6 & Liaoning & 1.055 & 0.943 & 1.063 & 0.992 & 0.995 \\
\hline 7 & Jilin & 1 & 1.015 & 1 & 1 & 1.015 \\
\hline 8 & Heilongjiang & 1 & 0.932 & 1 & 1 & 0.932 \\
\hline 9 & Shanghai & 1 & 0.979 & 1 & 1 & 0.979 \\
\hline 10 & Jiangsu & 0.984 & 0.997 & 1 & 0.984 & 0.981 \\
\hline 11 & Zhejiang & 1 & 1.020 & 1 & 1 & 1.020 \\
\hline 12 & Anhui & 0.946 & 0.960 & 0.945 & 1.001 & 0.908 \\
\hline 13 & Fujian & 1.122 & 0.990 & 1.118 & 1.003 & 1.110 \\
\hline 14 & Jiangxi & 1 & 0.976 & 1 & 1 & 0.976 \\
\hline 15 & Shandong & 0.999 & 0.914 & 1 & 0.999 & 0.913 \\
\hline 16 & Henan & 0.983 & 0.884 & 0.993 & 0.990 & 0.868 \\
\hline 17 & Hubei & 1 & 0.849 & 1 & 1 & 0.849 \\
\hline 18 & Hunan & 0.977 & 0.989 & 1.005 & 0.973 & 0.967 \\
\hline 19 & Guangdong & 1 & 1.040 & 1 & 1 & 1.040 \\
\hline 20 & Guangxi & 1.008 & 1.058 & 1.016 & 0.993 & 1.067 \\
\hline 21 & Hainan & 1 & 0.972 & 1 & 1 & 0.972 \\
\hline 22 & Chongqing & 1.018 & 0.994 & 1.017 & 1.001 & 1.012 \\
\hline 23 & Sichuan & 1 & 0.935 & 1 & 1 & 0.935 \\
\hline 24 & Guizhou & 0.925 & 0.856 & 0.932 & 0.993 & 0.792 \\
\hline 25 & Yunnan & 0.981 & 0.975 & 0.978 & 1.003 & 0.957 \\
\hline
\end{tabular}

Note: TFPC, total factor productivity changes; PTEC, pure technical efficiency changes; SEC, scale efficiency changes; TC, technological changes; TEC, technical efficiency changes 


\begin{tabular}{|lllllll|}
\hline No. & DMUs & TEC & TC & PTEC & SEC & TFPC \\
\hline 26 & Tibet & 1.013 & 1.792 & 1 & 1.013 & 1.816 \\
\hline 27 & Shaanxi & 1 & 0.996 & 1 & 1 & 0.996 \\
\hline 28 & Gansu & 1.020 & 1.024 & 1.024 & 0.996 & 1.045 \\
\hline 29 & Qinghai & 1 & 0.882 & 1 & 1 & 0.882 \\
\hline 30 & Ningxia & 1 & 0.890 & 1 & 1 & 0.890 \\
\hline 31 & Xinjiang & 1.049 & 0.935 & 1.041 & 1.007 & 0.981 \\
\hline Mean & & 1.001 & 0.983 & 1.003 & 0.998 & 0.984 \\
\hline $\begin{array}{l}\text { Note: TFPC, total factor productivity changes; PTEC, pure technical efficiency changes; SEC, scale } \\
\text { efficiency changes; TC, technological changes; TEC, technical efficiency changes }\end{array}$ \\
\hline
\end{tabular}

Table 3

Changes in the average of Malmquist indexes of LTCFs in China (2012-2016)

\begin{tabular}{|llllll|}
\hline & TEC & TC & PTEC & SEC & TFPC \\
\hline 2013 & 0.989 & 0.952 & 1.006 & 0.983 & 0.942 \\
\hline 2014 & 0.828 & 0.911 & 0.856 & 0.967 & 0.755 \\
2015 & 1.264 & 1.042 & 1.198 & 1.055 & 1.318 \\
2016 & 0.969 & 1.034 & 0.979 & 0.990 & 1.002 \\
\hline Mean & 1.001 & 0.983 & 1.003 & 0.998 & 0.984 \\
\hline Mean rank & 10.00 & 10.25 & 11.00 & 11.50 & 9.75 \\
\hline$X^{2}$ & 0.24 & & & & \\
\hline$P$ & 0.993 & & & \\
\hline $\begin{array}{l}\text { Note: } \text { TFPC, total factor productivity changes; PTEC, pure technical efficiency changes; SEC, scale } \\
\text { efficiency changes; TC, technological changes; TEC, technical efficiency changes. }\end{array}$ \\
\hline
\end{tabular}

\section{DEA Classification was used to compare the DEA efficiency value of the LTCFs in Eastern, Central and Western regions}

The regions were divided into three major classifications, namely Eastern (developed), Central (generally developed), and Western (underdeveloped) regions, which refers to the regional division in the China Health Statistics Yearbook. 
Supplementary Table 4 presented the means of TE of nursing homes in East, Central and West were 0.98, $0.93,0.91$ respectively; the means of PTE were $0.98,0.95,0.94$ respectively; the means of SE were 0.99 , $0.99,0.96$ respectively. The regions were divided into three major classifications, namely Eastern (developed), Central (generally developed), and Western (underdeveloped) regions, which refers to the regional division in the China Health Statistics Yearbook.

Table 4 presented PTE is significantly difference $(P=0.043)$, while TE and SE do not differ significantly among the nursing homes of Eastern, Central and Western regions from 2012 to 2016, as shown by the mean rank and Kruskal-Wallis test. The Mean rank of PTE and SE is the highest in the nursing homes of Eastern region, while the highest TE is in Western region.

As shown in the Supplementary Fig. 3, the efficiency values of the three regions all showed a trend of an initial decline, and then an increase, as the agency efficiency value reached the lowest point in 2014 . The Eastern region, in 2014, also showed a slight decline at first, and then gradually increase.

Table 4

Comparison of efficiency values of nursing homes among Eastern, Central and Western regions (2012 2016)

\begin{tabular}{|c|c|c|c|c|}
\hline & & Mean Rank & $x^{2}$ & $P$ \\
\hline \multirow[t]{3}{*}{ TE } & Eastern region & 8.60 & 1.12 & 0.572 \\
\hline & Central region & 6.30 & & \\
\hline & Western region & 9.10 & & \\
\hline \multirow[t]{3}{*}{ PTE } & Eastern region & 11.20 & 6.27 & 0.043 \\
\hline & Central region & 8.60 & & \\
\hline & Western region & 4.20 & & \\
\hline \multirow[t]{3}{*}{ SE } & Eastern region & 11.20 & 3.85 & 0.146 \\
\hline & Central region & 6.40 & & \\
\hline & Western region & 6.40 & & \\
\hline
\end{tabular}

\section{Projected value of non-effective nursing homes based on input-oriented in 2016}

Based on input-oriented (assuming that the output is unchanged), the CCR model was used to calculate the projected value of non-effective LTCFs in all provinces and municipalities in terms of inputs, the number of adjustments (actual value-projected value), and adjustment ratio[(adjusted number / actual value) $\times 100 \%$ ] of 15 non-effective LTCFs in provinces and municipalities in terms of investment are calculated. 
The results indicated that if the original output stay unchanged and the input is effectively optimized, it will result in the following: the number of beds in China's LTCFs can be reduced by 360038.9, the number of institutions can be reduced by 3464.9 , and the number of social work can be reduced by 497 , the total value of assets can be reduced by $87,0381.7$ yuan, and the number of employees can be reduced by 3,5465.9. (Supplementary Table 5)

\section{The efficiency values calculated by SBM and BCC models were used as the Tobit influencing factors in regression analysis}

The LTCFs with a greater number of women, social workers, and annual older people have a greater efficiency value. In addition, the more people within the age range of 35 and below, and 46 to 55 in the LTCFs, the lower efficiency value is. However, if the LTCFs with the greater number of people over the age of 56 , the efficiency value will be higher. (Table 5)

Table 5 Tobit regression analysis of the influential factors on TE of nursing homes

\begin{tabular}{|c|c|c|c|c|c|c|c|c|}
\hline \multicolumn{5}{|c|}{ SBM model } & \multicolumn{4}{|c|}{ BCC model } \\
\hline & coef. & Std.Err & $t$ & $P$ & coef. & Std.Err. & $t$ & $P$ \\
\hline cons. & $8.84 \mathrm{E}-01$ & 4.33E-02 & 20.4 & 0.00 & $9.44 \mathrm{E}-01$ & $4.10 \mathrm{E}-02$ & 23.1 & 0.00 \\
\hline \multicolumn{9}{|l|}{ Support factors } \\
\hline Entitled group ${ }^{\mathrm{a}}$ & $1.21 \mathrm{E}-05$ & $1.47 \mathrm{E}-05$ & 0.82 & 0.41 & $2.36 \mathrm{E}-05$ & $1.48 \mathrm{E}-05$ & 1.6 & 0.11 \\
\hline Strand group ${ }^{b}$ & $-6.76 \mathrm{E}-06$ & $4.16 \mathrm{E}-06$ & -1.6 & 0.11 & $-4.80 \mathrm{E}-06$ & 4.10E-06 & -1.2 & 0.24 \\
\hline Self-paid personnel $^{c}$ & $-7.08 \mathrm{E}-06$ & $4.45 \mathrm{E}-06$ & -1.6 & 0.11 & $-7.27 \mathrm{E}-06$ & 4.37E-06 & -1.7 & 0.10 \\
\hline Annual older adults ${ }^{d}$ & $1.01 \mathrm{E}-05$ & $4.02 \mathrm{E}-06$ & 2.5 & $0.01 *$ & $7.28 \mathrm{E}-06$ & $4.00 \mathrm{E}-06$ & 1.82 & 0.07 \\
\hline \multicolumn{9}{|l|}{ Management factors } \\
\hline Female $^{e}$ & $1.22 \mathrm{E}-04$ & 3.64E-05 & 3.35 & $0.00 * *$ & $1.48 \mathrm{E}-04$ & 4.71E-05 & 3.14 & $0.00 * *$ \\
\hline Techni & $-7.26 \mathrm{E}-05$ & $6.08 \mathrm{E}-05$ & -1.2 & 0.23 & $-5.87 \mathrm{E}-05$ & $6.20 \mathrm{E}-05$ & -1 & 0.35 \\
\hline College and above & $-1.06 \mathrm{E}-04$ & $7.21 \mathrm{E}-05$ & -1.5 & 0.15 & $-1.43 \mathrm{E}-04$ & $7.50 \mathrm{E}-05$ & -1.9 & 0.06 \\
\hline Age 35 and below ${ }^{f}$ & $-1.02 \mathrm{E}-04$ & $4.21 \mathrm{E}-05$ & -2.4 & $0.02 *$ & $-8.20 \mathrm{E}-05$ & $4.80 \mathrm{E}-05$ & -1.7 & 0.09 \\
\hline Age 35 to 45 & $2.88 \mathrm{E}-05$ & 4.29E-05 & 0.67 & 0.50 & $-4.23 \mathrm{E}-05$ & $4.65 \mathrm{E}-05$ & -0.9 & 0.37 \\
\hline Age 4 & $-1.83 \mathrm{E}-04$ & $4.98 \mathrm{E}-05$ & -3.7 & $0.00 * *$ & $-1.70 \mathrm{E}-04$ & $5.64 \mathrm{E}-05$ & -3 & $0.00^{* *}$ \\
\hline Age 56 a & $6.67 \mathrm{E}-05$ & $3.55 \mathrm{E}-05$ & 1.88 & 0.06 & $1.07 \mathrm{E}-04$ & $4.40 \mathrm{E}-05$ & 2.44 & $0.02 *$ \\
\hline Social workers & 2. $48 \mathrm{E}-04$ & $3.14 \mathrm{E}-04$ & 0.79 & 0.43 & $9.92 \mathrm{E}-04$ & $4.70 \mathrm{E}-04$ & 2.11 & $0.04 *$ \\
\hline Number & $1.99 \mathrm{E}-06$ & $2.92 \mathrm{E}-06$ & 0.68 & 0.50 & $3.13 \mathrm{E}-06$ & $4.59 \mathrm{E}-06$ & 0.68 & 0.50 \\
\hline Volunteer hours & $5.94 \mathrm{E}-07$ & $7.52 \mathrm{E}-07$ & 0.79 & 0.43 & $9.52 \mathrm{E}-07$ & $1.75 \mathrm{E}-06$ & 0.54 & 0.59 \\
\hline \multicolumn{9}{|l|}{ Environmental factor } \\
\hline Construction space $e^{\mathrm{g}}$ & $-5.11 \mathrm{E}-08$ & $2.81 \mathrm{E}-08$ & -1.8 & 0.07 & $-2.65 \mathrm{E}-08$ & $2.46 \mathrm{E}-08$ & -1.1 & 0.28 \\
\hline LR & 61.10 & & & & 63.88 & & & \\
\hline $\mathbf{R}^{2}$ & 0.38 & & & & 0.49 & & & \\
\hline
\end{tabular}

Note: $(\mathrm{a})$ = include 3 groups of old ex-serviceman: disable and sick person in revolutionary and veteran of nuclear war according to certain standard by monthly grant; (b) = exceptional poverty; (c) = at their own expense in institutions; $(d)=$ the number of patients in residential care annually; $(\mathrm{e})=$ the gender of employees; $(\mathrm{f})=$ the age of employees; $(\mathrm{g})=$ square kilometers of institutions. ${ }^{\star} P<0.05 ; * \star P<0.01$. 


\section{Discussion}

\section{Comprehensive efficiency evaluation}

The change of efficiency is the result of the interaction of PTE and SE. The results showed that $63.23 \%$ of LTCFs of 31 provinces achieves the effective PTE, which is consistent with previous research results various areas of China $[48,20]$, but lower than the average TE, PTE and SE of LTCFs in Xiamen [22], suggesting that the nursing homes in most of the areas in the country may have problems of insufficient utilization of constructions or lower TE. This might be associated with the unreasonable utilization of some LTCFs construction resources, as SE reflects the efficiency of production scale utilization.

As this study showed that there was a decreasing trend of nursing homes in effective TE from 2012 to 2014. The possible reasons behind for the decrease of the efficiency might be the blindly expanded the construction of nursing homes with less standardized management previously. However, China's Ministry of Civil Affairs effectively strengthen the policy support to build up pension service three years action plan (2014-2016). As for the standardized management, it has compiled local standards such as service standards for pension institutions, classification and evaluation of pension institutions, and formulated implementation rules for the establishment of pension institutions and measures for administration pension institutions to standardize the management system of pension institutions. Moreover, service reform was carried out by the national pension service comprehensive reform since 2014 [49]. A series of national policies laid a great foundation to promote economy and development motivation of pension institution by improving the service specification standards and national investment to expand the scale of the institution.

\section{Spatial, temporal and regional distribution analysis of the operational effectiveness of nursing homes in China}

Nursing homes in Beijing, Guangdong, Tianjin and other economically developed areas have always been technically efficient from 2012 to 2016. Referring to the guidelines for the quality inspection of nursing homes nationwide, the policy of "one district one case" and "one hospital one policy" have been adopted to make up for some existing shortcomings $[49,50]$. The results showed that nursing homes in Shandong province changed from being technical inefficiency in 2014 to an effective TE in 2015. The existing reasons behind might be that in 2014, the "China's 12th five-year plan for the development of undertakings for the elderly", and "Suggestions on accelerating the development of the elderly care service industry" were comprehensively implemented. Furthermore, the government has allocated services development special funds of 2.4 billion yuan to support the development of pension services industry of market-oriented polit area in Jilin, Shandong and other eight provinces [22]. All of these were done to effectively promote the nursing homes in Shandong in one year by means of a rapid rise from being technical inefficient into technical efficient.

TFPC of the sample nursing homes from 31 provinces declined by $2.14 \%$ during the 5 -year period. Although TEC has improved with an average of $0.1 \%$, the average $1.7 \%$ decrease of TC leads to the 
decrease of TFPC. Therefore, improving TC to boost TFPC is essential. The results obtained in the nursing homes of 31 provinces are not distinct. Torabipour et al [51] studied the productivity changes of hospitals in Ahvaz county from 2007 to 2010 and found that TC played a major role in productivity changes. Li explored the changes in efficiency and productivity of $45 \mathrm{THs}$ in Anhui Province and determined that the efficiency of these hospitals exhibited a downward trend from 2009 to 2011; TEC and TC also decreased by $3.8 \%$ and $14.1 \%$, respectively [52].According to the average of the efficiency change from 2012 to 2016, almost of the productivity index values of nursing homes improved from 2013 to 2015 , while the fluctuation of SE was not as strong as that of TE and PTE, with the relatively smaller SEC. This showed that the improvement of the productivity and TE of nursing homes has not kept pace with the development of the scale of institutions. The SEC of pension institutions in provinces like Hebei and Anhui was increasing, while the PTE and TC have declined to a certain extent. This was an indication that the SEC was too large that it weakened the functions of TE and TC in promoting economic growth.

\section{Comparison of TE of nursing homes in Eastern, Central and Western regions in China}

The TE, PTE, SE of nursing homes in Eastern regions were all the highest from 2012 to 2014. Nursing homes in East have a developed economy, with abundant health resources and a large number of excellent management talents, which can raise the level of efficiency of nursing homes. However, in the Central and Western regions, the service efficiency of institutions has decreased greatly, which is similar to the research results of Qian Haiyan [53]. There are also regional differences in the service efficiency of medical institutions, which are related to the results of the imbalance allocation of medical resources and multiple levels of economic development among Eastern, Central, and Western regions of China [54]. The service efficiency of nursing homes in the central area urgently needs to be improved overall. It is important to optimize organization management and break the development bottleneck caused by low TE. Health resources in Western regions are fewer than other regions and also with lowest service efficiency. Attentions should be paid to the balanced development of the Eastern, Central and Western regions. In the future, this should be the main concern.

\section{The adjustment of projected value for non-DEA effective nursing homes in 31 provinces and municipalities of China in 2016}

Five input indexes including the number of institutions, the number of employees at the end of the year, the original price of fixed assets, the number of social workers, the number of beds at the end of the year have to be adjusted to hit projected value. It was noticeable that the number of beds at the end of the year in non-DEA effective nursing homes needs to be improved the most, which indicated that the construction scale of nursing homes in some provinces were blindly expanded, while the beds occupancy rate of private nursing homes was lower, with amount of idle beds. All of these caused wasting amount of expenditure and capital [9]. A survey showed that there were more than 30 private residential cares in Chengdu, with a total of more than 8,000 beds with only 4,500 older people [55]. It was presented that only about half of the beds in the elderly care institutions in Chengdu urban area were applied, and $32.5 \%$ of the urban institutions in Tianjin, Harbin, Jinan, Wuhan and other cities are in deficit for a whole year, 
with an overall low bed occupancy rate [56]. The number of social workers also needs to be improved by $22 \%$, which is consistent with the current situation that China's integrated medical and nursing system is still far from perfect, the corresponding number of nursing staff is still small, and also the professional level is very low [57]. Social workers, as the mainstay resources to ensure the service quality, their competence can be applied to comprehensively evaluate nursing homes. The development of social workers needs the support of the government because of its relevant policies it can introduce. Also, it needs to attach importance to the prospects being trained in social work-related majors in colleges, universities and society, so as to ensure that highly qualified social workers can play an important role in manpower for the elderly care service [58].

\section{The analysis of factors affecting the efficiency of nursing homes, based on Tobit model}

The efficiency value of nursing home was influenced by variable factors. The results presented that the age of the employees has an influence on the efficiency value. The more employees who are aged 56 and above, the efficiency value gets to be higher, as employees in this age might get higher level of professional ability. However, those who are around 40 years old, do not have any sense of longevity with their jobs due to their lack of sufficient skills [59]. They are expected to have more patience and dedication to elderly care, so that the elderly can obtain better service quality to improve the outputs and efficiency of nursing homes in the process [22]. A study showed that social workers play an important role in resource integration, emotional supplement, communication and coordination, spiritual support, social function and also in managing of nursing homes. This situation reflects the inadequacy of competent personnel, which resulted in the decline of the efficiency in the social work services [60]. The government should strengthen the support for the development of social workers by setting up policies, standards and norms to ensure that highly competent social workers can fill in the manpower needed by elderly service institutions. Rosko et al. (1995) conducted a research in Pennsylvania, which presented that the occupancy rate of institutions affected the service efficiency [61]. As the pension industry development information asymmetry, it is easy to find the phenomenon of vacant beds and a bed at in different regions. The bed occupancy rate significantly affects the service efficiency, that is, for every $1 \%$ increase in occupancy rate, the comprehensive efficiency of pension institutions will increase by $0.871 \%$ [62].

\section{Strengths And Limitations}

This study combined DEA method and Tobit model to comprehensively evaluate the performance and influencing factors of nursing homes in China, based on panel data. As it is representative of the overall country, which can improve the understanding of the complex efficiency issues in the different regions of China.

However, this study should be interpreted in light of several potential limitations. In this paper, there are restricted variables due to data limitations. Even though we compensate the limitations of previous studies to include outcome quality, further research should be conducted and include more variables of 
the quality of care. Since DEA is a data-oriented method, the efficiency values obtained are directly affected by the combination of inputs and outputs applied. However, further research should explore the standardized criteria and mechanism to appropriately selected to measure the efficiency of decisionmaking units, for example, qualitative studies could be applied to explore the reasons for the changes in TE and productivity.

\section{Conclusions}

This study provides an empirical representation of the efficiency and productivity changes of nursing homes in the process of advancing the marketization of pension services in China. As the improvement of the productivity and TE of nursing homes has not kept pace with the development of the scale of institutions, the adverse alteration in TC and PTEC should be emphasized. The TE, PTE, SE of nursing homes in Eastern regions were all the highest. Among these three efficiency values, TE of nursing homes is lowest due to the higher SE of nursing homes in China. The results showed that the influencing factors of in nursing homes might include gender and age of employees, the number of social workers, the number of older people in a year. It was suggested that the country have to attach great importance to the cultivation and improvement of the professional level, educational background and experiences of the professionals for elderly care, so as to meet the diversified needs of different types of elderly groups.

\section{Abbreviations}

TE: Technical Efficiency; DEA: Data Envelopment Analysis; BCC model: Banker-Charnes-Cooper model; SBM model: Slacks-Based Measure model; PTE: Pure Technical Efficiency; SE: scale efficiency; TFPC: Total Factor Productivity Changes; LTCFs: Long-term care facilities; TC: Technological Changes; PTEC: Pure Technical Efficiency Changes.

\section{Declarations}

\section{Ethics approval and consent to participate}

Not applicable

\section{Consent for publication}

Not applicable

\section{Availability of data and materials}

Data are available through the China Civil Affairs statistical yearbook from $\Downarrow$ https://www.yearbookchina.com/navibooklist-n3020013350-1.html.

\section{Competing interests}


The authors declare that they have no competing interests.

\section{Funding}

This study was supported by the National Natural Science Foundation of China (grant number 81973144) and the China Postdoctoral Science Foundation (grant number 2020M671949).

\section{Authors' contributions}

Author YH, LWZ and YF worked together. LWZ and YH were in charge of the study design. YF analyzed and interpreted the data, and drafted the manuscript. YH and LWZ participated in the statistical analysis and manuscript drafting. YF supervised and revised the manuscript. All authors have revised, read and approved the final manuscript.

\section{Acknowledgements}

The authors would like to thank the National Bureau of statistics of the People's Republic of China, for its support with the data. We are also grateful to the National Natural Science Foundation of China, the China Postdoctoral Science Foundation and School of Public Health, Xiamen University, for their supporting to our study.

\section{References}

1. World Report on Ageing and Health, 2019. A global guide to livable cities for the elderly. https://www.who.int/zh/news-room/fact-sheets/detail/ageing-and-health.

2. National Bureau of Statistics of the People Republic of China, 2019. Population Statistics. https://www.citypopulation.de/php/chinashandongadminc.php?adminc.php?adm2id-=370202.

3. China public welfare research institute, 2017. China Economic Net. Report on China's pension service personnel training in 2017: There is a huge gap in the demand of talents for the elderly services in China. https://www.sohu.com/a/158839704_759437

4. UNESCAP, 2015. Long-term Care for Older Persons in China. SDD-SPPS PROJECT, Working Papers Series: Long-Term Care for Older Persons in Asia and the Pacific. http://www.unescap.org/ourwork/social-development/gender-equality

5. China family development report, 2015. National Health Commission of the People's Republic of China. http://www.nhc.gov.cn/xcs/spbd/201505/ce6159ebba55485e996938407c70d6a6.shtml

6. Ministry of Civil Affairs of the People's Republic of China, 2017. http://www.mca.gov.cn/

7. CPC central committee and State Council, 2019. The state actively responds to a medium - and longterm plan for an aging population. https://www.sohu.com/a/358146526_778107

8. Ministry of Civil Affairs of the People's Republic of China, 2019. Document of the ministry of civil affairs on accelerating the construction of old-age service system and promoting the harmonious 
development of

society. http://www.mca.gov.cn/article/gk/jytabljggk/zxwyta/201911/20191100020878.shtml

9. Jie, Ren. 20 Study on the efficiency of institutional pension service in Xiamen city. Population and economy. 02, 58-68.

10. Qianqian, Li. 2017. Research on urban institutional pension model based on healthy aging index. Liaoning university.

11. Feng Z, Guan X, Feng X, Liu C, Zhan H, Mor V 2014. Long-term care in China: reining in market forces through regulatory oversight. Cambridge: Cambridge University Press, 409-443.

12. W, Lili, Pengyao D and Wei K. 2017. Review and analysis on the present development of long - term care facilities in China during the 12th five year plan. Aging science research (04), 13-24-43.

13. Fizel, John L. and Thomas S. Nunnikhoven. 1992. Technical Efficiency of For-Profit and Non-Profit Nursing Homes. Managerial \& Decision Economics. 13(5), 429-439.

14. Bjrkgren, Magnus A., Unto Hkkinen and Miika Linna. 2001. Measuring Efficiency of Long-Term Care Units in Finland. Health Care Management Science. 4(3), 193-200.

15. Garavaglia, Giulia, Emanuele Lettieri, Tommaso Agasisti and Silvano Lopez. 2011. Efficiency and quality of care in nursing homes: an Italian case study. Health Care Management Science. 14(1), p.22-35.

16. Valdmanis, Vivian, Michael Rosko, hervé Leleu and Dana Mukamel. 2016. Assessing overall, technical, and scale efficiency among home health care agencies. Health Care Management Science.

17. Delellis, Nailya $O$ and Yasar A Ozcan. 2012. Quality outcomes among efficient and inefficient nursing homes: A national study. Health Care Management Review. 38(2).

18. Min A, Park CG, Scott LD. Evaluating Technical Efficiency of Nursing Care Using Data Envelopment Analysis and Multilevel Modeling. West J Nurs Res. 2016 Nov;38(11):1489-1508. doi:

10.1177/0193945916650199. Epub 2016 Jul 9. PMID: 27222512.

19. Shuyi, $C$ and T Yang. 2017. Long-term care institutions develop "bottlenecks" and crack in Shandong of China. Chinese population science. Chinese population science. 02, 115-125+128.

20. Ying, Z and C Zhejun. 2015. Ningbo long-term care agency efficiency evaluation. Journal of Ningbo University. 03, 79-84.

21. Jian, $L$ and S Siliang. 2013. An empirical study on the influencing factors of the performance of China's pension service. Chinese Journal of Management. 2, 58-62.

22. Zhang, L., Zeng, Y. \& Fang, Y. Evaluating the technical efficiency of care among long-term care facilities in Xiamen, China: based on data envelopment analysis and Tobit model. BMC Public Health 19, 1230 (2019). https://doi.org/10.1186/s12889-019-7571-x

23. China statistical yearbook, 2013-2017. http://www.stats.gov.cn/tjsj/ndsj/

24. Cheng, Zhao Hui, Hong Bing Tao, Miao Cai, Hai Feng Lin and Ru Ning Zhang. 2015. Using a twostage data envelopment analysis to estimate the efficiency of county hospitals in China: a panel data study. Lancet. 386(8), S64. 
25. Nayar, Preethy and Yasar A. Ozcan. 2008. Data Envelopment Analysis Comparison of Hospital Efficiency and Quality. Journal of Medical Systems. 32(3), 193-199.

26. Charnes, Cooper, Lewin and Seiford. 1997. Data Envelopment Analysis Theory, Methodology and Applications. Journal of the Operational Research Society.

27. Charnes, A., W. W. Cooper and E. Rhodes. 1978. Measuring the efficiency of decision making units. European Journal of Operational Research. 2(6), 429-444.

28. Banker, R. D., A. Charnes and W. W. Cooper. 1984. Some Models for Estimating Technical and Scale Inefficiencies in Data Envelopment Analysis. Management Science. 30(9), 1078-1092.

29. Morita, Hiroshi, Koichiro Hirokawa and Joe Zhu. 2005. A slack-based measure of efficiency in context-dependent data envelopment analysis. Omega. 33(4), 357-362.

30. Cooper, William W., Lawrence M. Seiford and Kaoru Tone. 2007. Data Envelopment Analysis: A Comprehensive Text with Models, Applications, References and DEA-Solver Software. Doi: 1007/9780-387-45283-8.

31. Mogha, Sandeep Kumar, Shiv Prasad Yadav and S. P. Singh. 2014. SBM-DEA Model Based Efficiency Assessment of Public Sector Hospitals in Uttarakhand, India.

32. Mukherjee N, Chatterjee B. 2019.Poverty and Inequality in Urban India with Special Reference to West Bengal: An Empirical Study[M]// Internal Migration, Urbanization and Poverty in Asia: Dynamics and Interrelationships.

33. Ying, Chu Ng. 2011. The productive efficiency of Chinese hospitals. China Economic Review. 22(3), 0439.

34. Malmquist, Sten. 1953. Index numbers and indifference surfaces. Trabajos De Estadistica. 4(2), 209242.

35. Scott, E., AtkinsonPaul, W. and Wilson. 1995. Comparing mean efficiency and productivity scores from small samples: A bootstrap methodology. Journal of Productivity Analysis.

36. Grosskopf, Shawna, Bjorn Lindgren and P. Ross. 1989. Productivity Development in Swedish Hospitals: A Malmquist Output Index Approach. Methodology and Applications. Kluwer Academic Publishers. 27.

37. Troutt, M.D., Arun Rai and Aimao Zhang. 1996. The potential use of DEA for credit applicant acceptance systems. Computers \& Operations Research. 23(4), 405-408.

38. Seiford, Lawrence M. and Joe Zhu. 1998. An acceptance system decision rule with data envelopment analysis. Computers \& Operations Research. 25(4), 329-332.

39. RD, Banker, Charnes A and Cooper WW. 1984. Some models for estimating technical and scale ineGciencies in data envelopment analysis. Management Science. 30(9), 1078-1092.

40. Laine, Juha, Miika Linna, Unto H?Kkinen and Anja Noro. 2005. Measuring the productive efficiency and clinical quality of institutional long-term care for the elderly. Health Economics. 14(3), 245-256.

41. Gerdtham, U. G., M. L?Thgren, M. Tambour and C. Rehnberg. 1999. Internal markets and health care efficiency: a multiple-output stochastic frontier analysis. Health Economics. 8(2), 151-164. 
42. G, Shimshak D, Lenard M L and Klimberg R K. 2009. Incorporating quality into data envelopment analysis of nursing home performance:a case study. 37(3), 672-685.

43. Ying, $Z$ and $C$ Zhejun. 2015. Ningbo long-term care agency efficiency evaluation. Journal of Ningbo University. 03, 79-84.

44. Bloom, Bernard S., Ronald J. Vogel and Hans C. Palmer. 1984. Long-Term Care: Perspectives from Research and Demonstrations. Journal of Policy Analysis \& Management. 3(4).

45. Olesen, O. B and N. C Petersen. 1995. Incorporating quality into data envelopment analysis: a stochastic dominance approach. International Journal of Production Economics. 39(1-2), 117-135.

46. Lim, Ji Young, Kim, Mi Ja, Park, Chang Gi, Kim and Jung Yun. 2011. Evaluation of Efficiency of Community Visiting Health Service Units - A Demonstration of Using Data Envelopment Analysis (DEA). Journal of Korean Academy of Nursing Administration. 17(1).

47. Harrison, Jeffrey P. and Sean Meyer. 2014. Measuring Efficiency Among US Federal Hospitals. Health Care Manag. 33(2), 117-127.

48. L, Jian and Siliang S. 2013. An empirical study on the influencing factors of the performance of China's pension service Chinese Journal of Management (2), 58-62.

49. Ministry of Civil Affairs of the People's Republic of China, 2014. http://www.mca.gov.cn/.

50. Huaxia, Zhao. 2014. Comprehensive reform of the elderly service industry in 42 pilot regions. Friends of the elderly comrades monthly (11), 14 .

51. Torabipour, Amin, Maryam Najarzadeh, Mohammad Arab, Freshteh Farzianpour and Roya Ghasemzadeh. 2014. Hospitals Productivity Measurement Using Data Envelopment Analysis Technique. Iranian Journal of Public Health. 43(11), 1576-1581.

52. Li, C. 2013. Evaluating Efficiency of Township Hospital in Anhui Province Based on Data Envelopment Analysis. Jinan: Shandong University.

53. Haiyan, Qian and Shen Fei. 2014. Evaluation of financial expenditure efficiency of local government purchasing services: a case study of Hefei municipal government purchasing home-based old-age care services. Financial research (03), 64-67.

54. Min, Wu. 2011. Research on the development status of institutional pension services from the perspective of demand and supply. Beijing: economic science press.

55. Chengdu working committee on aging office, 2010. Annual report of the legal person of the institution. http://www.cdswbb.gov.cn/ndbgsy/Detail.aspx?id=3899.

56. Baoding civil affairs information network, 2015. China pension institutions development research report: surveyed pension institutions about $30 \%$ of the loss. http://www.bdmzj.gov.cn/WWW/Mod/Detail.aspx?city=130601\&id=4444,2015-07-17.

57. Feng, Zhanlian, Elena Glinskaya, Hongtu Chen, Sen Gong, Yue Qiu, Jianming Xu and Winnie Yip. 2020. Long-term care system for older adults in China: policy landscape, challenges, and future prospects. The Lancet. 396(10259), 1362-1372.

58. Xiyu, Liu. 2020. Current situation of social workers. Think tank era,(09), 289-291. 
59. Christine, Mueller, Arling Greg, Kane Robert, Bershadsky Julie, Holland Diane and Joy Annika. 2006. Nursing home staffing standards: Their relationship to nurse staffing levels. Gerontologist. 46(1), 7480.

60. Evans, Sherrill, Peter Huxley, Claire Gately, Martin Webber, Alex Mears, Sarah Pajak, Jibby Medina, Tim Kendall and Cornelius Katona. 2006. Mental health, burnout and job satisfaction among mental health social workers in England and Wales. The British journal of psychiatry: the journal of mental science. 188, 75-80.

61. Rosko, Chilingerian, A Jon, Aaronson and J. Zinn. 1995. Rosko, M., Chilingerian, Jon A., Aaronson, W., and Zinn, J., "The Effects of Ownership and Environmental Pressure on Nursing Home Efficiency," Medical Care, October 1995. Medical Care. 26(1), 145.

62. Chaoyang, Sun. 2019. Research on service efficiency and influencing factors of elderly care institutions in yantai. Cooperative economy and technology(20), 174-177.

\section{Figures}



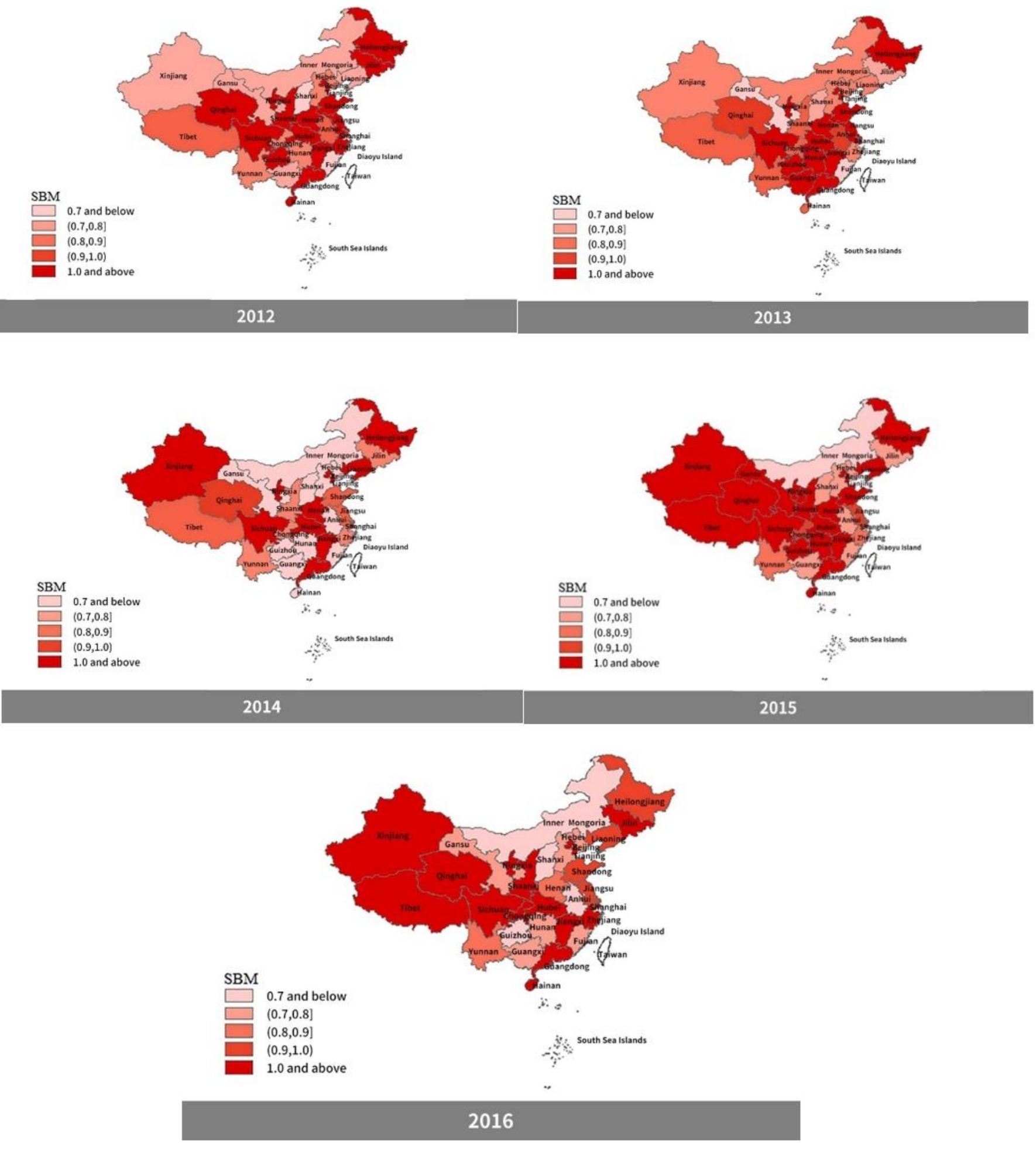

\section{Figure 1}

The distribution of TE in the LTCFs in 31 provinces of China (2012 to 2016). (Note: Map comes from Ministry of Natural Resources of the People's Republic of China, http://bzdt.ch.mnr.gov.cn/) Note: The designations employed and the presentation of the material on this map do not imply the expression of any opinion whatsoever on the part of Research Square concerning the legal status of any country, 
territory, city or area or of its authorities, or concerning the delimitation of its frontiers or boundaries. This map has been provided by the authors.

\section{Supplementary Files}

This is a list of supplementary files associated with this preprint. Click to download.

- SupplementaryMaterial.docx 